\title{
Medicinal Plants with antioxidant Potential: A review
}

\author{
Khaled Rashed \\ Pharmacognosy Department, National Research Centre, Dokki, Giza, Egypt.
}

Article history: Received: 14 November 2013, revised: 20 December 2014, accepted: 11January 2014, Available online: 3 April 2014

\begin{abstract}
Plan: This review deals with the antioxidant potential of some medicinal plants.

Methodology: Plants contain a wide variety of free radical scavenging molecules, such as polyphenols, dietary glutathione, vitamins and endogenous metabolites. An attempt has been made in this review to identify the major medicinal plants with antioxidant activity.

Outcome: We provide information concerning the complete profile of 18 selected medicinal plants on their antioxidant activity. Keywords: Medicinal plants, antioxidant activity, phytochemicals.
\end{abstract}

\section{INTRODUCTION}

An antioxidant is a molecule capable of slowing or preventing the oxidation of other molecules. They may protect cells from damage caused by unstable molecules known as free radicals. Antioxidants terminate these chain reactions by removing free radical intermediates, and inhibit other oxidation reactions by being oxidized themselves. Free radicals are fundamentals to any biochemical process and represent an essential part of aerobic life and metabolism. Majority of the diseases are mainly linked to oxidative stress due to free radicals ${ }^{1}$.

Our body is rich in endogenous antioxidants, the substances that have the ability to stop free radicals formation or to limit the damage they cause ${ }^{2}$. The effectiveness of current used exogenous antioxidants arises most probably from the increase of the endogenous free radical scavengers as enzymes (superoxide dismutase and selenium-dependent glutathione peroxidase), vitamins (alpha tocopherol and ascorbic acid). Many plants have been also found to posses free radical scavenging activity (Polyphenols, alkaloids and terpenoids). Low levels of one or more of the essential antioxidants have been shown to be associated with many disorders including cancer, inflammation, atherosclerosis, coronary heart disease and diabetes.

Thus, in such cases, the administration of exogenous antioxidants seems to be salutary. Nowadays, a great deal of effort being expended to find effective antioxidants for the treatment or prevention of free radical-mediated deleterious effects ${ }^{3}$. This review gives good information on medicinal plants with antioxidant potential.

For Correspondence: khalednabih2015@yahoo.co.uk

Contact: 01003642233

Hygeia.J.D.Med. Vol.6 (1), April 2014@ 2014 all rights reserved.

Hygeia journal for drugs and medicines, 22293590,09756221

Rid: J-3090-2013 
1. Rhizophora mangle is a plant from Rhizophoraceae family. The bark extract of the plant showed scavenging activity of hydroxyl radicals and the extract contained polyphenols, carbohydrates and sterols ${ }^{4}$.

2. Diospyros malabarica is a plant from Ebenaceae family. The bark is used for the treatment of fever and fruit juices for healing of wound ulcer ${ }^{5}$. The stem extract of the plant competes with oxygen to react with nitric oxide and thus, inhibits the generation of anions. The main phytoconstituents in the extract are phenolic compounds ${ }^{5}$.

3. Asparagus racemosus is a tree from Liliaceae family. It shows antioxidant activity through the free radical scavenging, superoxide anion radical scavenging, hydrogen peroxide scavenging, nitric oxide scavenging, metal chelation, reduction power and inhibition of lipid peroxidation in rats. The main phytoconstituents are saponins, alkaloids and flavonoids ${ }^{6}$.

4. Auricularia auricular is a tree and known as 'tree ear or wood ear' from Auriculaceae family: It has shown a potent hydroxyl radical scavenging and lipid per-oxidation inhibitory activities. The main phytoconstituents are flavonoids ${ }^{7}$.

5. Eucalyptus globules is a tree and known as "Karpura maram" from Myrtaceae family. The antioxidant activity of Eucalyptus oil was estimated by two in vitro assays namely diphenyl picryl hydrazyl radical scavenging activity and inhibition of ascorbate induced lipid peroxidation method ${ }^{8}$.

6. Acacia arabica is a plant from Mimosae family. The antioxidant assays were carried out in vivo and in vitro experimental models. In vitro, lipid peroxidation was carried out by tertiary butyl hydroperoxide (TBH) induced lipid peroxidation. In vivo, experiments were carried out in $\mathrm{CCl}_{4}$-induced hepatotoxicity in rats. The bark of the plant contained quercetin, (+) catechin, (-) epicatechin and gallic acid. The polyphenol rich active fraction of Acacia arabica is a potent free radical scavenger and protects TBH induced lipid peroxidation and $\mathrm{CCl}_{4}$-induced hepatic damage. The bark is used in the treatment of asthma, bronchitis, diabetes, dysentery and skin diseases ${ }^{9}$.

7. Ligustrum vulgare is a plant from Oleaceae family. The leaves antioxidant activity was evaluated using DPPH test. The main phytoconstituents are flavonoids, iridoids, coumarins and essential oil, where flavonoid aglycones are responsible for the antioxidant activity and it shows a potent free radical scavenging activity ${ }^{10}$.

8. Terminalia chebula is a tree and known as Myrobalanus chebula. Combretaceae family. The main phytoconstituents are tannins, chebulinic and gallic acids. The extract was tested by studying the inhibition of radiation induced lipid peroxidation in rat liver microsomes. It shows free radical scavenging activity due to presence of tannins and also It inhibits the development of duodenal ulcer and so the extract has appeared to show a cytoprotective effect on the gastric mucosa ${ }^{11}$.

9. Lobelia nicotianaefolia is a plant from Campanulaceae family. The chemical constituents are alkaloids as lobeline and also it contains volatile oil, resin, gum and fixed oil. It is mainly used in the treatment of asthma and as respiratory stimulant ${ }^{8}$.

10. Citrus lemon is a tree from Rutaceae family. The antioxidant activity was estimated by two in vitro assays, DPPH radical scavenging activity and inhibition of ascorbate induced lipid peroxidation (LPO) method. The main phytoconstituents are citral and limonene. The antioxidant property is shown due to the presence of $\mathrm{citral}^{8}$. 
11. Decalepis hamiltonil is a plant from Asclapiadaceae family. The plant extract was tested by various model systems like DPPH, $\beta$-carotene linoliate and hydroxyl radical scavenging activity. This is act by easing the level of endogenous defenses by up regulating the expression of genes encoding the enzymes such as superoxide dismutase (SOD), catalase (CAT) or glutathione peroxidase (GTX). The main phytoconstituents responsible for the antioxidant activity are 2-hydroxyl-4-methoxy benzaldehyde ${ }^{12}$.

12. Origanum syriacum L., a very popular Arab spice, (Lamiaceae family) is an aromatic, herbaceous and perennial plant growing wild in the Sinai Desert of Egypt.. The leaves of $O$. syriacum have been used as a herbal traditional medicine, flavor and fragrance, and for aromatherapy in the form of bath, massage, steam inhalation and vaporization. It is used in teas and cooked or baked foods ${ }^{13}$. The essential oil from the leaves showed a good antioxidant and 2,2-diphenyl-1-picrylhydrazyl (DPPH) radical-scavenging activities ${ }^{14}$.

13. Majorana hortensis is a perennial herb of the Mediterranean region commonly called as majoram, belonging to the Lamiaceae family (mint). It is an aromatic plant and due to its aroma, it has culinary uses. The plant extract has several therapeutic uses such as curing digestive disorders, treats fevers and is used as an expectorant. The fresh leaves of this candidate plant are used to study the free radical scavenging activity ${ }^{15}$.

14. Rosemary (Rosmarinus officinalis) L. is a very important medicinal and aromatic plant, which belongs to the Lamiaceae family and has been cultivated for a long time in ancient Egypt, China and India. Rosemary is a widely used aromatic and medicinal plant nowadays. It has antibacterial, antioxidant and antiphlogistic effect. Rosemary is cultivated for the valuable oil which can be extracted from the harvested plants when flowers are in buds. It is well known that the activity of rosemary extracts in food industry and medicine due to the presence of some important antioxidant oil and phenolic components ${ }^{16}$.

15. Lemon grass (Cymbopogon citrates) is an aromatic perennial tall grass with rhizomes and densely tufted fibrous root. It is found in countries such as Australia, China, India, Africa (Egypt). It is used for gastrointestinal problems. Lemon grass tea was used against flu, fever, pneumonia, and to solve gastric and sudorific problems. It is considered as antitussive, antiseptic, sudorific, stomachic, anti-rheumatic and to treat backache, sprain and haemoptysis. Several studies proved that Lemon grass has high antioxidant capacity ${ }^{17}$.

16. Thyme (Thymus vulgaris) is an important medicinal plant belongs to Lamiaceae family. It is recognized by its therapeutic virtues ${ }^{18}$. It has been used for centuries as spice, home remedy, drug, perfume and insecticide. In medicine, it is used as antispasmolytic, antibacterial, antifungal, secrotolytic, expectorant, antiseptic, antlelmintic and antitussive. The leaves of Thyme has an antioxidant potential and the major phytoconstituents are flavonoids ${ }^{18}$.

17. Calendula officinalis Linn, is an aromatic herb belongs to Asteraceae family. It is mainly used because of its various biological activities to treat diseases like analgesic, antidiabetic and antiinflammatory. It is also used for eye disease, skin injuries and in some cases of burn. $C$. officinalis contains carotenoids and triterpenic alcohols, both in their free and esterified forms and polyunsaturated fatty acids, such as calendic acid. An extract of $C$. officinalis was evaluated for its antioxidant potential by oral administration of alcoholic extract inhibited superoxide generation in macrophages in female swiss albino mice by $12.6 \%$ and $38.7 \%$ at doses of 100 and $250 \mathrm{mg}=\mathrm{kg}$ b. wt ${ }^{19}$. 
18. Artemisia апnиa L. is a vigorous growing annual weedy herb. Its main phytoconstituents are flavonoids, coumarins, steroids, phenolics, purines, lipids, aliphatic compounds, monoterpenoids, triterpenoids and sesquiterpenoids. Thus far, the most important of the sesquiterpenoids seems to be artemisinin, dihydroartemisinic acid, artemisinic acid and arteannuin B. The essential oil of Artemisia annua aerial parts, consisting of camphor (44\%), germacrene D (16\%), trans-pinocarveol (11\%), $\beta$-selinene $(9 \%), \beta$-caryophyllene $(9 \%)$ and Artemisia ketone (3\%), was screened for its antimicrobial activity. The essential oil remarkably inhibited the growth of tested Gram-positive bacteria Enterococcus hirae and both tested fungi. This oil has shown an antioxidant activity equivalent to $18 \%$ of the reference compound $(\alpha-$ tocopherol). ${ }^{20}$

\section{REFERENCES}

1. Velavan, S., Nagulendran, K., Mahesh, R., "In vitro antioxidant activity of Asparagus racemosus root", Pharmacog Mag. 2007; 3:26-33.

2. Tomas-Barberan, F.A., Robins, R.J. Phytochemistry of Fruits and vegetables. Caledon Press, Oxford, New York, 1997.

3. Reiter, R.J. and Robinson, G.D. Free Radicals, Bantam Book, USA, 1995; 24.

4. Sanchez, J., Melchor, G. “Antioxidant activity of Rhizophora mangle barks”, Fitoterapia 2006; 77:181-186.

5. Mondal SK., Chakraborty G. "In vitro antioxidant activity of Diospyros malabarica bark", Ind. Jr. Exp. Biol. 2006; 44:39-44.

6. Velavan, S., Nagulendran, K., Mahesh, R. "Invitro antioxidant activity of Asparagus racemosus root", Pharmacog Mag. 2007;3:26-33.

7. Acharya, K., Samui, K., Rai, M., "Antioxidant and nitric oxide synthatase activation properties of Auricularia auricular", Ind. Jr. Exp. Biol. 2004; 42:538-540.

8. Kokate C.K.(b), Purohit A.P., "Text book of Pharmacognosy”, 2004; 29, Pp. 317-318, 336-337.

9. Sundaram, R., Mitra, S.K. "Antioxidant activity of ethyl acetate soluble fraction of Acacia arabica bark in rats", Ind. Jr. Pharmacol. 2007; 39:33-38.

10. Nagy, M., Sersen, F. "Free radical scavenging activity of different extracts and some constituents from the leaves of Ligustrum vulgare and L. delavayanum", Fitoterapia 2006; 77:395-397.

11. Jagetia, G.C. "The evaluation of the radio protective effect of Triphala in the mice exposed to $\gamma$-radiation", Phytomedicine 2002; 9:99-108.

12. Murthy, K.N.C., Rajasekaran, T. “Antioxidant property of Decalepis hamiltonil”. Ind. Jr. Exp. Biol. 2006, 44:832837.

13. Alam M.H., Mavi, A., Yildirim A., Digrak M., Hirata T. Biol. Pharm. Bull 2003, 26, 1725 - 1729.

14. Mehmet, H. A., Ahmet M., Ali Y., Metin D., Toshifumi, H. Screening Chemical Composition and in Vitro Antioxidant and Antimicrobial Activities of the Essential Oils from Origanum syriacum L. Growing in Turkey. Biol. Pharm. Bul 2003; 26(12) 1725-1729.

15. Radha, P., Padma, P. R. Free Radical Scavenging Activity of Majorana hortensis leaves. Ancient Sci Life 2011; 30(4): 96-99.

16. Eva, S.-B., Maria, H. T., Attila H., Csilla, R., Ilona S. V. Antioxidant effect of various rosemary (Rosmarinus officinalis L.) clones. Acta Biologica Szegediensis 2003; 47(1-4):111-113. 
17. Vanisha, S. N., Hema, M. Potential Functions of Lemon Grass (Cymbopogon citratus) in Health and Disease. International Journal of Pharmaceutical and Biological Archives 2012; 3(5):1035-1043.

18. Zeghad, N., Merghem, R. Antioxidant and antibacterial activities of Thymus vulgaris L. Medicinal and Aromatic Plant Research Journal 2013;1(1),5-11.

19. Mukesh, KS., Pankaj S., Nagori, K., Kumar, D. Dewangan, TA . Alexander, H. Badwaik, Tripathi DK. Organoleptic properties in-vitro and in-vivo pharmacological activities of Calendula officinalis Linn: Journal of Chemical and Pharmaceutical Research 2011;3(4):655-663.

20. Fabien, J., Veronique, M., Jean, M. B., Michel, D., Josette, V. Antibacterial and antioxidant activities of Artemisia annua essential oil. Fitoterapia 2002; 73:532-535. 